\title{
Simultaneous Use of Targeted Radiotherapy with External Beam Radiotherapy in the Treatment of Bone Metastasis
}

\author{
Kemik Metastazı Tedavisinde Hedefleyici Radyoterapinin Eksternal Ișın Radyoterapisi ile \\ Eșzamanlı Kullanımı
}

\section{Yasemin Benderli Cihan}

Kayseri City Education and Research Hospital, Department of Radiation Oncology, Kayseri, Turkey

I cancer patients, skeletal system metastases are the third most localized organ after lung and liver. 70\% of bone metastases (BM) involve the axial skeleton and are mostly multiple. The most common area is the vertebrae. Metastases to the bone are mostly caused by breast, prostate, lung, kidney and thyroid cancers. ${ }^{1}$ Prolonged survival in patients with BM due to developments in cancer treatment and waiting for complications in one of every three cases with bone involvement reveal the importance of an appropriate treatment approach ${ }^{1-3}$. In our previous study on 181 cases, the rate of bone metastasis was seen most frequently in lung, breast and prostate cancer. In terms of anatomical distribution, the vertebra, lower extremity and upper extremity were found to be the metastatic location, respectively ${ }^{1}$. With early diagnosis and treatment, the patient's quality of life will be improved by reducing possible complications such as pain, fracture, hypercalcemia and spinal cord compression that may occur due to BM. Pain is a common symptom in CM and decreases the quality of life. Studies show that cancer patients experience severe pain at a rate of $30 \%$ at the time of diagnosis and $60-90 \%$ at the advanced stage ${ }^{2-4}$.

Treatment of BM is done by palliative methods. Local treatments (surgery and radiotherapy), systemic treatments (cytotoxic chemotherapy, hormonotherapy, bisphosphonates, gallium nitrate, etc.) and supportive treatments (analgesics, psychological support and social support) are the main methods used ${ }^{2-6}$. Depending on the prevalence of the disease, the severity of the symptoms, previous treatments, and concomitant diseases, one of these treatment methods or its combined use is preferred. A limited number of BM can be treated with surgery and/or radiotherapy (RT). In more diffuse bone involvement, radiopharmaceuticals, hormones and chemotherapeutics are more preferred. Each treatment has its own advantages and disadvantages. The use of analgesics for these long periods is limited due to their side effects. It has been reported that the palliation provided by chemotherapeutics or hormonotherapy does not occur in a short time and is not effective and long-lasting ${ }^{4-7}$.

The purpose of RT in the treatment of BM is to prevent or relieve the symptoms and dysfunctions of the patient for the rest of his life. RT is used for palliative and prophylactic purposes. Palliative application in bone pain, pathological fracture formation, peripheral nerve compression and spinal cord compression. Prophylactic application is applied in cases with risk of cord compression and pathological fracture. RT is usually used to reduce pain due to BM. After treatment, pain response usually begins in the first 48 hours. It becomes apparent within four weeks. This is a permanent response in $70 \%$ of the patients ${ }^{2,3,4-7}$. With RT, $80-90 \%$ of the patients respond to pain, while $40-60 \%$ of them provide full control. In lesions, it provides symptomatic improvement in $96 \%$ and recalcification in $78 \%{ }^{7}$. 
Nowadays, radionuclide therapy is successfully applied in refractory metastatic pain. Multiple metastatic foci can be treated simultaneously with radionuclide therapy. The radioisotope administered intravenously to the body shows its therapeutic effect by reaching all targets in the body that show osteoblastic or mixed bone activity. Therefore, this treatment method is also called "targeted radiotherapy". With this treatment, it improves the quality of life by reducing pain in the patient. It reduces the need for analgesics, RT and chemotherapy. It also improves the course of the disease and survival ${ }^{3,5,6,8}$. Although the idea of using bone targeted radioisotopes for the treatment of common BM in the advanced stage of the disease is dominant. These agents are also used in the early stages of diseases in order to increase the response to treatment in the early metastatic period'. With the targeted radiotherapy method, the complete or partial success rate varies between $60 \%$ and $90 \%$, respectively. Pain control can usually start in the first days of treatment, or it may take up to the second or third week. Retreatment can be safely performed on days when there is no adequate response to treatment or when pain begins to recur after successful treatment ${ }^{6,8}$.

P-32 and Sr-89 radioactive isotopes are the first radiopharmaceuticals used in radionuclide treatments. Clinical use of P-32 has been restricted due to its high energy, the prominence of its side effect of myelotoxicity and longterm beta scattering in the tissue. Sm-153, Re-186, Re-188, which are newly developed radioisotopes that spread beta over time, have taken their places in routine practice ${ }^{5,10}$. The most common complication is myelotoxicity. It is recommended to reduce the dose by $50 \%$ in patients with moderate renal impairment (GFR $>30$ and $<50 \mathrm{~mL}$ / $\min )^{4,6,11}$. Although all beta emitting isotopes show different physical properties, the superiority of radionuclides used in the treatment of BM has not been demonstrated in clinical studies. Patient-dependent characteristics appear to be the determining factor in the choice of radionuclide in routine practices.

There is contradiction in the literature regarding which of the external RT or radionuclide treatments are more effective and reliable. The effect of radionuclide therapy on survival is controversial. Studies have shown that the effect of radioisotopes used in palliation of pain is not much different from external $\mathrm{RT}^{3,12}$. In the study of Buchali et al. ${ }^{13}$ comparing the $\mathrm{Sr}-89$ treatment group with placebo in patients with prostate cancer, it was reported that $\mathrm{Sr}-89$ treatment prolonged the survival ${ }^{13}$. In addition, in randomized and multi-center studies conducted in Europe, it has been reported that $\mathrm{Sr}-89$ treatment decreases the life span in painful metastatic bone cancers compared to local RT applications ${ }^{12}$. In another study, it was reported that $\mathrm{Sr}-89$ increases the quality of life in the patient, but does not affect the life span $^{2}$.

Nowadays, combined therapies have come into question in cases where pain due to BM cannot be adequately controlled with the treatments applied. There are a limited number of studies in the literature on this subject. One of them is the use of radionuclide treatments (Re 186 HEDP or Sm 153) together with external RT. Hiçsönmez et al. ${ }^{3}$ examined the efficacy of combined therapy in 33 cancer patients with painful BM and in patients who were given systemic radionuclide therapy after localized external radiotherapy. They stated that between Re 186 HEDP and Sm 153 hematological toxicity was not high and there was no difference in response to treatment. They also reported that combined therapy reduced pain and analgesic intake. In the study conducted by Heianna et al. ${ }^{4}$, they reported that $\mathrm{Sr}-89$ was effective and safe in cases requiring simultaneous emergency treatment with external radiotherapy for more than one CM. In a randomized controlled study involving 126 prostate cancer patients by Porter \& McEwan, in the study where RT and Sr-89 were used in combination, they reported no contribution to survival, but the number of new pain zones was significantly lower for the group receiving $\mathrm{Sr}-89^{14}$. In another study, it was reported that when adjuvant is used, Sr-89 does not contribute additionally in areas receiving external RT, but prevents pain in areas with CM.

As a result, bone pain caused by skeletal system metastases is the most common type of chronic pain seen among cancer patients. Treatment of bone pain secondary to metastasis is difficult and requires a multidisciplinary approach. This multidisciplinary approach includes treatments such as pain relievers, hormone treatments, chemotherapy, bisphosphonates, RT and systemic radionuclide. Simultaneous use of radionuclide external beam RT in pain palliation in multiple BM seems to be an effective and safe treatment option in cases requiring emergency treatment. However, clinical studies are needed to better evaluate the follow-up and treatment of cancer patients in these combined treatment applications. 


\section{References}

1. CihanYB, Sarı̈ö T, Arslan A. Role of season in overall survival of patients with bone metastasis undergoing radiotherapy. Transl Cancer Res 2016;5(1):85-88.

2. James N, Pirrie S, Pope A, Barton D, Andronis L, Goranitis I, et al. TRAPEZE: a randomised controlled trial of the clinical effectiveness and cost-effectiveness of chemotherapy with zoledronic acid, strontium-89, or both, in men with bony metastatic castration-refractory prostate cancer. Health Technol Assess. 2016 Jul;20(53):1-288. doi: 10.3310/hta20530. PMID: 27434595 Clinical Trial.

3. Hicsonmez A, Kucuk ON, Andrieu MN, Guney Y, Ibis E. Role of Radionuclide Therapy as Adjuvant to Palliative External Beam Radiotherapy for Painful Multiple Skeletal Metastasis. World J Oncol 2010 Aug;1(4):158-166. doi: 10.4021/wjon235w. Epub 2010 Aug 29.PMID: 29147199.

4. Heianna J, Toita T, Endo W, Kasuya G, Ariga T, Hashimoto S, et al. Concurrent use of strontium-89 with external beam radiotherapy for multiple bone metastases: early experience. Ann Nucl Med 2015 Dec;29(10):848-53. doi: 10.1007/s12149-015-1010-6. Epub 2015 Aug 13.PMID:26266885.

5. Liepe K, Franke WG, Kropp J, Koch R, Runge R, Hliscs R. Comparison of rhenium-188, rhenium-186-HEDP and strontium-89 in palliation of painful bone metastases]. Nuklearmedizin 2000 Sep;39(6):146-51.PMID: 11057405 Clinical Trial. German.

6. Heron DE, Brufsky A, Beriwal S, Kurman M. Myelotoxicity of samarium Sm 153 lexidronam in patients receiving prior treatment with chemotherapy or radiotherapy. Ann Oncol2008 Sep;19(9):1639-43. doi: 10.1093/annonc/mdn178. Epub 2008 May 7.PMID:18467311.

7. Blitzer PH. Reanalysis Of The RTOG Study Of The Palliation Of Symtomatic Osseous Metastasis. Cancer 1985;55(7):1468-72.

8. Sadremomtaz A, Masoumi M. An assessment of bone-seeking radionuclides for palliation of metastatic bone pain in a vertebral model. Ann Nucl Med 2019 Apr;33(4):252-264. doi: 10.1007/s12149-019-01329-w. Epub 2019 Jan 18.PMID: 30659480.

9. Kraeber-Bodere F, Campion L, Rousseau C, Rousseau C, Bourdin S, Chatal JF, et al. Treatment Of Bone Metastases Of Prostate Cancer With Strontium-89 Chloride: Efficacy in Relation to the Degree of Bone Involvement. Eur J Nucl Med 2000;27:1487-93.

10. Ayati N, Aryana K, Jalilian A, Hoseinnejad T, Samani AB, Ayati Z, et al. Treatment efficacy of (153)Sm-EDTMP for painful bone metastasis. Asia Ocean J Nucl Med Biol 2013 Spring;1(1):27-31. doi: 10.7508/aojnmb.2013.01.006.PMID:27408839.

11. Paravati AJ, Russo AL, Aitken C. Adverse events in the long-term follow-up of patients treated with samarium Sm 153 lexidronam for osseous metastases. Int J Radiat Oncol Biol Phys 2011 Oct 1;81(2):506-10. doi: 10.1016/j.ijrobp.2010.05.066. Epub 2010 Oct 1.PMID: 20888141.

12. Oosterhof GO, Roberts JT, de Reijke TM, Engelholm SA, Horenblas S, Maase HVD et al. Strontium (89) Chlorid Eversus Palliative Local Field Radiotheraphy in Patients with Hormonal Escaped Prostate Cancer; a Phase III Study of the European Organisation for Research and Treatment of Cancer, Genitourinary group. Eur Urol 2003;44:519-26.

13. Buchali K, Correns HJ, Schuerer M, Lips H, Sydow K. Results of a Duble Blind Study of Strontium-89 Theraphy of Skeletal Metastases of Prostatic Carcinoma. Eur J Nucl Med 1988;14:349-51.

14. Porter AT, McEwan AJ. Strontium-89 as an adjuvant to external beam radiation improves pain relief and delays disease progression in advanced prostate cancer: results of a randomized controlled trial. Semin Oncol 1993;20(3 Suppl 2):38-43.

15. Porter AT, McEwan AJ, Powe JE, Reid R, McGowan DG, Lukka H, et al. Results of a randomized phase-III trial to evaluate the efficacy of strontium-89 adjuvant to local field external beam irradiation in the management of endocrine resistant metastatic prostate cancer. Int $\mathrm{J}$ Radiat Oncol Biol Phys 1993;25(5):805-813. doi: 10.1016/0360-3016(93)90309-J. 